\title{
MOLECULAR MARKER ASSISTED HEAVY METAL RESISTANCE ANALYSIS OF PHYSIOLOGICAL GENES IN NATURAL PLANTS - TAKING RICE AS AN EXAMPLE
}

\author{
GAO, J. \\ Department of Life Sciences, Lvliang University, Lvliang 033001, China \\ (e-mail: gaojiaojiao2019@163.com) \\ (Received $3^{\text {rd }}$ Sep 2019; accepted $12^{\text {th }}$ Feb 2020)
}

\begin{abstract}
At present, heavy metal pollution seriously threatens the survival and development of natural plants, so it is necessary to use a molecular marker-assisted method to select natural plant physiological genes, select good breeding, and enhance the heavy metal resistance of natural plants. Heavy metal resistance of natural plants was studied, which heavy metal resistance of rice mainly included blast resistance and stripe blight resistance. To study rice blast resistance, improved SDS extraction method was used to extract rice DNA. The obtained DNA solution could be directly used as a template to start PCR amplification. In the study of resistance to stripe blight, the varieties of stripe blight and rice were used as resistance donor parents and resistance receptor parents. The resistance of hybrid plants was identified through hybridization and backcross marker-assisted selection. The results showed that molecular marker-assisted method could identify rice germplasm resources containing Pib gene. Among $18 \mathrm{BC} 2 \mathrm{~F} 3$ lines carrying homozygous resistance genes, the disease grade index was 16.0 at the highest level and 0.45 at the lowest level. The resistance level to stripe blight belonged to resistant. The reharvested Indica rice had better resistance to stripe blight, which could significantly enhance its heavy metal resistance.
\end{abstract}

Keywords: molecular markers, natural plants, physiological genes, heavy metals, rice, stripe blight resistance

\section{Introduction}

Heavy metal pollution is in the focus of attention for the world nowadays, mostly concerning the harmfulness of heavy metals to natural plants. Natural plants are the energy, temperature, humidity, light and fresh water obtained by photosynthesis from the sun are the basic needs of plant survival, rice is one of the natural plants. On the one hand, heavy metals are permanently released into the environment and can accumulate slowly in natural plants (Gherib et al., 2017); on the other hand, most heavy metals are not essential elements of natural plants. When the content of heavy metals reaches the tolerance level of a natural plant, excessive heavy metals can destroy the structural components of natural plants, thereby threatening the survival of natural plants. As people pay more attention to the hazards of heavy metals, the remediation technology of heavy metal contaminated soil emerges. Traditional remediation methods for heavy metals have their own defects (Huang et al., 2017). Measures such as guest soil, covering soil and passivator cost a lot but have little effect. At the same time, new pollutants may be introduced to cause more serious harm. Bioremediation technology has become the mainstream remediation technology (Wang et al., 2018a) because of its advantages of wide materials, low price, strong adsorption capacity and easy management. Nowadays, bioremediation technology is taking Rhizobium of leguminous plants as a new research trend to assist natural plants to resist heavy metal stress. Although the new repair methods can overcome most of the drawbacks of traditional repair methods, the research is still in its infancy. In terms of provenance, the 
Rhizobium of leguminous plants in natural growth state has little or no ability to assist natural plants in resisting heavy metal uptake, while the practical application effect of leguminous plants with high resistance obtained by gene technology is not clear (Kusch et al., 2016). Whether the community of rhizobia and natural plants has the ability to activate heavy metals in the surrounding environment is not clear; besides the heavy metals absorbed by natural plants, many new problems such as whether the residual heavy metals are harmful to human beings and the environment have not been solved (Liang et al., 2017). In addition, as a new land remediation method, resistant natural plants (organisms with high accumulation and low absorption) have attracted wide attention since 1950s. With the further study at molecular level, it has been found that not only the external characteristics of plants will change under the stress of heavy metals, but also the resistance genes in natural plants response to heavy metal stress by expressing transcriptional proteins. The mechanisms and models of these natural plants have been gradually explored and applied in variety breeding, food safety and land remediation (Shah et al., 2017). In a word, in recent years, the research on heavy metalresistant natural plants mainly focuses on the screening and marking of resistance genes, analyzing the degree of heavy metal resistance in natural plants, screening out natural plants with strong heavy metal resistance, improving the heavy metal resistance of natural plants and improving the growth status of natural plants (Wang et al., 2018b).

Natural plant resistance refers to the ability of natural plants to adapt to adversity. The acquisition of resistant materials plays a key role in elucidating the whole biological resistance research (Wang et al., 2017). It has been found that natural plants can be identified as stress-resistant by observing their living conditions under stress. They have a wide range of sources, stable heredity, and can adapt to different environments through sexual and asexual reproduction. Therefore, they have become the most common experimental material in scientific research (Wang et al., 2016), which is currently used for research. The main heavy metal-tolerant plants are Rhodiola, centipede, ryegrass and cash crops such as rice and rye. As far as the tolerance of natural plants to heavy metals is concerned, natural plants of different families and genera show different abilities. Generally speaking, woody natural plants have the best tolerance to heavy metal stress (Danilova et al., 2016). Mench et al. studied the responses of common tobacco, yellow tobacco and maize to cadmium stress. The results showed that different natural plants had different tolerance to cadmium due to different physiological metabolism, and the resistance of tobacco was stronger than that of maize. Common tobacco has stronger cadmium resistance than yellow tobacco. Mench et al. also showed that there was a positive correlation between the cadmium stress intensity and heavy metal activation ability of these two tobacco species. Therefore, the heavy metal resistance of natural plants could be analyzed by observing the tolerance of different natural plants and varieties under different concentration gradients of heavy metal stress. However, this method takes a long time and can be used to analyze the heavy metal resistance of natural plants. The observation process is susceptible to the influence of external environment (Beohar et al., 2018). In view of the fact that rice blast strains cannot be shared among the major rice-producing regions in the world, it is difficult to identify the alleles of disease-resistant genes in different rice germplasm resources. With the emergence and rapid development of DNA molecular marker technology, marker-assisted selection technology has become an effective way to select disease-resistant genes correctly. However, the recombination rate between diseaseresistant genes and molecular markers varies greatly in different populations, and the 
population constructed with molecular markers is often not a breeding material, which has certain limitations in practical application. In addition, because these molecular markers themselves are aimed only at genes, there may be unconnected situations in a large number of population breeding, leading to the failure of disease-resistant gene selection (Jimenez et al., 2016). Therefore, the best way is to use the disease-resistant gene sequence itself to establish the corresponding molecular markers, quickly and accurately analyze the genetic composition of individuals at the molecular level, so as to realize the direct selection of genotypes, molecular breeding, and obtain natural plants with strong resistance to heavy metals.

Heavy metal resistance of physiological genes of natural plants includes many kinds, and different kinds of heavy metal resistance of natural plants are different. Molecular marker assistant method can significantly improve the accuracy of predicting disease resistance and heavy metal toxicity, salt damage, drought resistance, dry resistance and heat resistance of natural plants. Taking rice as an example, the heavy metal resistance of rice was studied.

\section{Materials and methods}

\section{Analysis of rice blast resistance}

\section{Test material}

Choosing China as the experimental country, the tested rice materials were 122 parents or breeding intermediate materials of hybrid rice such as IRBLb-B, F-145-2 and 93-11, Shuhui 363, Shuhui 527 and D62B. IRBLb-B and F-145-2 were provided by Dr. Lei Cailin, Institute of Crop Science, Chinese Academy of Agricultural Sciences; 93-11 was an indica rice cultivar bred by Jiangsu Lixia River Institute of Agricultural Sciences. IRBLb-B and F-145-2 are monoclonal resistance Pib genetic materials bred by recurrent parents in Heigu, Lijiang New Regiment, while 93-11 does not contain Pib gene. Therefore, IRBLb-B and F-145-2 were used as resistant parents and 93-11 as susceptible parents.

The remaining 120 materials are parents or breeding intermediate materials of hybrid rice developed by Rice Research Institute of Sichuan Agricultural University in recent years. In March 2017, six hybrid combinations were prepared in Yangzhou with IRBLb-B and F-145-2 as female parents, Shuhui 363, Shuhui 527 and D62B as male parents. F1 was planted in Sichuan in the summer of the same year. In September 2017, 100 seeds of each F2 combination were selected for disease resistance test at the Rice Research Institute experimental site of Yangzhou Agricultural University.

\section{Molecular marker-assisted selection}

Firstly, Molecular marker-assisted selection (MAS) was used to link resistance genes, and DNA was extracted from resistance genes. The improved SDS method was used to extract DNA. Specific methods are as follows:

a) Take about the leaves of the tender green rice, cut them into grain-sized fragments and put them into a $2 \mathrm{ml}$ centrifugal tube. Sprinkle liquid nitrogen into the tube and quickly smash it with plastic chopsticks (Hu et al., 2016).

b) $400 \mathrm{ml}$ SDS buffer (1 M Tris-Hcl PH8.0, 0.5 M EDTA PH8.0, Nacl, SDS) was added to the tube, and the tube was heated for $30 \mathrm{~min}$ at 65 (?) $\mathrm{C}$, during which 
three to four oscillations occurred, and the mixture of SDS in the tube blade was dark green.

c) Add $100 \mu \mathrm{KAc}$ (glacial acetic acid adjusts $\mathrm{PH}$ to 8.0 with $\mathrm{NaOH}$ ) to the tube, mix evenly and insert the centrifugal tube into the ice cube, and rest for $30 \mathrm{~min}$.

d) $600 \mu \mathrm{l}$ chloroform isoamyl alcohol (24:1) was added to the tube. After homogeneous mixing, it was placed in the shaker and continued to oscillate for $30 \mathrm{~min}$.

e) $8000 \mathrm{rpm}$ was centrifuged for $10 \mathrm{~min}$. The supernatant (about $400 \mathrm{l}$ ) was removed and put into $1.5 \mathrm{ml}$ centrifugal tube.

f) Add $600 \mu \mathrm{l}$ absolute ethanol which is pre-cooled at $-20{ }^{\circ} \mathrm{C}$ and put it in the refrigerator at $-20{ }^{\circ} \mathrm{C}$ for overnight.

g) $1200 \mathrm{rpm}$ centrifugation for $15 \mathrm{~min}$, discarding supernatant, visible at the bottom of the tube gray-white precipitation adherence.

h) Add $400 \mu \mathrm{l}$ TE buffer (1M Tris-Hcl PH8.0, 0.5M EDTA), dissolve precipitation by oscillation, and keep the refrigerator in reserve at $-20{ }^{\circ} \mathrm{C}$. The obtained DNA solution can be directly used as a template for PCR amplification.

\section{PCR amplification}

Polymerase chain reaction (PCR) amplification primers, using the Pib dominant molecular marker reported by Concetta, can specifically amplify the corresponding fragment sequence of the disease-resistant allele Pib. At the same time, using the sequenced indica rice variety 93-11 and the sequence corresponding to the Pib gene as the susceptible sequence, the polymorphism design of the disease-resistant gene Pib on the DNA sequence can specifically amplify (Salgaonkar et al., 2016). The name, sequence, location and expected size of the primers used for PCR amplification are shown in Table 1.

Table 1. Primer names and sequences for PCR reactions

\begin{tabular}{c|c|c|c|c}
\hline Primer name & PibdomF & PibdomR & Lys145F & Lys145R \\
\hline $\begin{array}{c}\text { Order } \\
\text { Sequence (5'-3') }\end{array}$ & $\begin{array}{c}\text { GAACAATGCCCAAA } \\
\text { CTTGAGA }\end{array}$ & $\begin{array}{c}\text { GGGACCACATGTCAGT } \\
\text { GaGC }\end{array}$ & $\begin{array}{c}\text { TGGGTGCCTCGGTAGTC } \\
\text { AGT }\end{array}$ & $\begin{array}{c}\text { GGGAAGCGGATCCTA } \\
\text { GGTCT }\end{array}$ \\
\hline Location & $8669-8720^{*}$ & $9016-8996^{* *}$ & $37285710-37285729^{* * *}$ & $37286477-37286458^{* * *}$ \\
\hline Expect size (bp) & & \multicolumn{2}{|c}{803} \\
\hline
\end{tabular}

* represents the polymorphism of the disease-resistant gene Pib is shown below. ** represents the location of specific primer sequence in the Pib resistance gene. See GenBank accession No. AB013448 for details. *** represents the location of specific primer sequence in indica rice 93-11 corresponding to Pib gene

The primer sequence was synthesized by Yingjun Biotechnology Co., Ltd. The PCR reaction system was $25 \mu \mathrm{l}$, containing $2.5 \mu \mathrm{l} 10 \times \mathrm{Buffer}, 2.0 \mu \mathrm{dNTP}, 3.0 \mu \mathrm{l} 4 \mathrm{~mol} \cdot \mathrm{L}^{-1}$ positive and reverse primers, $0.2 \mu \mathrm{l} 4 \mathrm{U} \cdot \mu^{-1}$ Taq enzyme, $3.0 \mu \mathrm{l} 20 \mathrm{ng} \cdot \mu \mathrm{l}^{-1}$ template DNA and $14.3 \mu \mathrm{l}$ pure water. The procedure of PCR was as follows: pre-denaturation at 94 for $5 \mathrm{~min}$, denaturation at 94 for $45 \mathrm{~s}$, annealing at 55 for $45 \mathrm{~s}$, extension at 72 for $1.5 \mathrm{~min}$, and extension at 72 for $10 \mathrm{~min}$. The amplified products were electrophoretic in $3 \%$ agarose gel, stained with ethidium bromide and photographed under ultraviolet light. When 122 parents or materials of hybrid rice and $600 \mathrm{~F} 2$ plants tested in early stage were detected by PCR, each sample was repeated three times. 


\section{Gel preparation and electrophoresis}

The PCR products were electrophoretic by $8 \%$ polyacrylamide amide non gel. The basic procedures were as follows:

1. Clean the glass plate with deionized water and wipe it with degreased cotton dipped in absolute ethanol.

2. Insert the glass plate into the plastic pad as required, and then seal the gap in the lower part of the school with $1 \%$ agar.

3. After agar solidification, about $35 \mathrm{ml}$ of collocated propylene-clozamine solution, $25 \mu 1$ TEMED, $150 \mu \mathrm{AP}$, were injected into the glass panels, and the comb was inserted.

4. The comb was pulled out and poured into the $1 \times \mathrm{TBE}$ electrophoretic buffer after $30 \mathrm{~min}$ of standing for gel coagulation. Clear the bubbles in the sample hole (Dong et al., 2019).

5. $2 \mu \mathrm{l} 6 \times$ Loading Buffer was added to the amplified products of each tube of PCR. After mixing, 1.51 sample was injected into the dot hole with a microsampler.

6. Connect the electrophoresis apparatus with the electrophoresis cell, adjust the voltage to $250 \mathrm{~V}$, and electrophoresis for about $2 \mathrm{~h}$.

7. After electrophoresis, remove the glass plate from the electrophoresis tank and remove the gel carefully.

8. Rinse the gel two times in the steamed water and transfer it to $0.1 \% \mathrm{AgNO}_{3}$ solution, then put it on the shaking table and shake $12 \mathrm{~min}$ to dye it.

9. Remove the gel and transfer it to the distilled water for two times, then pour into the chromogenic solution for color rendering.

10. Take out the gel and wrap it with fresh-keeping film and scan the results.

\section{Preparation of bacterial solution and identification of resistance to rice scar}

The strains resistant to Pib gene were 05-7 (ZA13), 05-12 (ZB13), 05-3 (ZB15), 0530 (ZC15), 05-16 (ZD7), 05-23 (ZE3), 05-2 (ZF1), 05-11 (ZG1) and so on. 122 parents of hybrid rice and $600 \mathrm{~F} 2$ plants tested in early stage were identified by single inoculation. The rice genotype strains were 05-12 (ZB13) and 05-30 (ZC15). The tested strains were provided by Plant Protection Laboratory of Rice Research Institute of Sichuan Agricultural University. The strain culture and the preparation of bacterial solution were carried out according to the introduced methods. Rice blast resistance (Peng et al., 2017) was determined according to the international classification criteria for rice blast resistance evaluation. The evaluation classification criteria are shown in Table 2.

The resistance to rice blast was analyzed according to Table 2 . The selected samples were identified for natural induced disease resistance in the field. The infected plants were found in the field, and the disease spot length was measured to identify the level of resistance to rice blast.

\section{Resistance to rice stripe blight}

\section{Test material}

The selected indica rice varieties were selected in the "Materials and methods" section. 
Table 2. Evaluation and classification criteria

\begin{tabular}{|c|c|c|}
\hline $\begin{array}{l}\text { Resistance } \\
\text { level }\end{array}$ & Leaf plague standard & $\begin{array}{c}\text { Standard of panicle } \\
\text { neck plague }\end{array}$ \\
\hline \multirow{3}{*}{ Resist (R) } & 0 leaf is disease-free & 0 Disease-free panicle \\
\hline & $\begin{array}{l}1 \text { The leaf blade has brown spots and is smaller in diameter than } \\
\qquad 0.5 \mathrm{~mm}\end{array}$ & $\begin{array}{l}1 \text { Ear blast rate less } \\
\text { than } 1 \%\end{array}$ \\
\hline & 2 Leaf blade has oval brown spot, diameter between $0.5-1 \mathrm{~mm}$ & \multirow{3}{*}{$\begin{array}{l}3 \text { Panicle blast rate } \\
1 \% \leq 5 \%\end{array}$} \\
\hline \multirow{2}{*}{$\begin{array}{l}\text { Medium anti- } \\
\quad(\mathrm{MR})\end{array}$} & $\begin{array}{l}3 \text { The blade has an elliptical lesion, the center is off-white, the } \\
\text { edge is brown, and the diameter is between } 1 \mathrm{~mm} \text { and } 2 \mathrm{~mm}\end{array}$ & \\
\hline & $\begin{array}{l}4 \text { The fusiform spot is between } 1-2 \mathrm{~mm} \text { and limited to two veins, } \\
\text { and the damage area is less than } 2 \%\end{array}$ & \\
\hline \multirow{2}{*}{ Moderate (MS) } & 5 Typical disease spot, damage area $3 \% \leq 10 \%$ & \multirow{2}{*}{$\begin{array}{l}5 \text { The ear blast rate } \\
\text { was } 6 \% \text { and } 25 \% \text {. }\end{array}$} \\
\hline & 6 Typical disease spot, damage area $11 \% \leq 25 \%$ & \\
\hline Susceptible (S) & 7 Typical disease spot, damage area $25 \% \leq 50 \%$ & $\begin{array}{l}7 \text { Panicle blast rate } \\
25 \% \leq 50 \%\end{array}$ \\
\hline \multirow{2}{*}{$\begin{array}{l}\text { High sensitivity } \\
\qquad \text { (HS) }\end{array}$} & 8 Typical lesions, $51 \% 75 \%$ of the area & \multirow{2}{*}{$\begin{array}{l}9 \text { Ear blast rate } \\
51 \% \leq 100 \%\end{array}$} \\
\hline & 9 All leaves withered to death & \\
\hline
\end{tabular}

\section{Marker-assisted selection and backcross breeding}

In the main season of 2017, indica rice was crossed with Dular in Yangzhou, and backcross combinations were made in Sichuan in the same winter. $\mathrm{BC}_{1} \mathrm{~F}_{1}$ was sown in Sichuan in 2017 and molecular marker-assisted selection was initiated to screen plants carrying disease-resistant genes for further backcross with indica rice. In order to speed up the breeding generation and ensure the normal germination of hybrid seeds, the hybrid seeds were dried immediately after harvest, disinfected and germinated on the culture medium. $\mathrm{BC}_{2} \mathrm{~F}_{1}$ seedlings were added to Sichuan in early November 2017, and $\mathrm{BC}_{2} \mathrm{~F}_{1}$ plants carrying disease resistance genes were screened by molecular markers to continue backcrossing and harvesting self-crossing seeds (Chen et al., 2017). $\mathrm{BC}_{3} \mathrm{~F}_{1}$ and $\mathrm{BC}_{2} \mathrm{~F}_{2}$ seeds were planted in Sichuan in January 2017 after the seeds were harvested and dried, and the second season was planted. BC3F1 contains $\mathrm{BC} 3 \mathrm{~F} 1, \mathrm{BC} 2 \mathrm{~F} 2, \mathrm{BC} 2 \mathrm{~F} 3$. The plants carrying disease resistance genes were selected from $\mathrm{BC}_{3} \mathrm{~F}_{1}$ and the seeds of $\mathrm{BC}_{3} \mathrm{~F}_{1}$ and $\mathrm{BC}_{2} \mathrm{~F}_{2}$ were harvested. $\mathrm{BC}_{4} \mathrm{~F}_{1}, \mathrm{BC}_{3} \mathrm{~F}_{2}, \mathrm{BC}_{2} \mathrm{~F}_{3}$ and indica rice were sown in Sichuan in 2018. The disease resistance was identified and the important traits were investigated. According to the resistance and comprehensive traits, the good and the bad were selected and eliminated. Considering that the cytoplasm and backcross thicknesses of Indica Rice need to be preserved in the backcross progenies, indica rice is the female parent for each cross and backcross.

\section{DNA extraction and molecular marker analysis DNA}

The extraction method of DNA is the same as that of the above 2.1.3 section extraction method. After DNA extraction, PCR is amplified by molecular marker assisted, then glued and electrophoretic, and observed and read under ultraviolet lamp and BIORAD gel imager (Song, 2017). The band type assignment of parents is 1, Dular band type assignment is 3, F1' band type assignment is 2 and default band assignment is 0 . 


\section{Evaluation of disease resistance}

Natural insecticidal inoculation was used for identification. When a large number of rice planthoppers migrated to the seedlings, they were treated three times a day to make the seedlings uniformly poisoned. Before transplanting, the incidence of rice plants was investigated. In this study, two criteria for disease resistance identification were used: one was the incidence of disease, i.e. the ratio of the number of plants with disease to the total number of plants; the other was the disease grade index. According to Washio's criteria for resistance identification, the plants were divided into six grades, namely $A, B, B t, C r, C$ and $D$. The disease grade of each inoculated plant was investigated (Sun et al., 2018), and then according to the criteria, the disease grade index was divided into six grades. The following formula calculates the disease grade index of each strain according to the disease grade.

$$
B_{j}=\frac{(100 \times A+80 \times B+60 \times B t+40 \times C r+20 \times C+5 \times D)}{Z_{z}}
$$

In the formula, $B j$ represents disease grade index. $Z z$ tests the total number of seedlings. $A, B, B t, C r, C$ and $D$ in the formula are calculated by substituting the number of plants with different symptoms. The resistance of inoculated seedlings can be divided into resistance ( $\mathrm{R}, 0-29)$, moderate resistance (MR, 30-39), moderate susceptibility ( $\mathrm{S}$, 40-69) and high susceptibility (HS, 70-100) according to disease grade index.

\section{Character determination}

$\mathrm{BC}_{4} \mathrm{~F}_{1}, \mathrm{BC}_{3} \mathrm{~F}_{2}$ and $\mathrm{BC}_{2} \mathrm{~F}_{3}$ were planted in Sichuan in the season of 2018 . The parents of indica rice were planted on May 10 and transplanted on June $10 . \mathrm{BC}_{4} \mathrm{~F}_{1}$ plants were planted to the full, $\mathrm{BC}_{3} \mathrm{~F}_{2}$ plants were planted to $50, \mathrm{BC}_{2} \mathrm{~F}_{3}$ plants were planted to 100 , with a row spacing of $16.7 \mathrm{~cm} \times 26.7 \mathrm{~cm}$. After heading in late August, the heading date was recorded and harvested in time after maturity. The plant height, flag leaf length, leaf angle of flag leaf (angle between base of flag leaf and main stem), panicle length of main stem, total grain number of main stem panicle, panicle curvature (angle between neck node and apex of panicle and vertical axis of panicle), 1000 of homozygous disease-resistant plants detected in $\mathrm{BC}_{4} \mathrm{~F}_{1}$ population and $\mathrm{BC}_{3} \mathrm{~F}_{2}$ population were investigated at harvest time. Seven agronomic traits with high heritability such as grain weight (Li et al., 2017).

$\mathrm{BC}_{2} \mathrm{~F}_{3}$ strains with homozygous resistance genes were observed and evaluated in detail from heading to maturity, and excellent strains were selected. After maturation, $20 \mathrm{BC}_{2} \mathrm{~F}_{3}$ strains were selected to investigate yield traits such as yield per plant, panicle number per plant, total grains per panicle, number of solid grains per panicle, seed setting rate and 1000-grain weight, and 5 of them were selected to investigate plant height, flag leaf length, flag leaf width, flag leaf angle, panicle-leaf difference (distance between spike tip of main stem and flag leaf tip), stem. The agronomic traits included basal diameter (stem diameter at $1 \mathrm{~cm}$ of the main stem of stripped leaf sheath), neck diameter (axis diameter at $1 \mathrm{~cm}$ above the neck node), ear length of the main stem, total grain number of the main stem ear, and ear curvature. The chalky grain rate and chalkiness of rice were measured by $\mathrm{BC}_{2} \mathrm{~F}_{3}$ mature seeds. Starch viscosity spectrum was measured by 3-D RVA instrument produced by Newport Scientific Instrument Company, Australia. 


\section{Results}

\section{Resistance analysis of rice blast}

Anti-Pib gene spectrum

In order to verify the validity of molecular marker assisted resistance gene in this method, it is necessary to analyze whether Pib gene has any utilization value in disease resistance breeding. 16 near strains of IRBLb-B and F-145-2 were used to spray two near isogenic lines. The results of the analysis were shown in Table 3, using sham you 63 , a common susceptible variety.

Table 3. Analysis results

\begin{tabular}{c|c|c|c}
\hline \multirow{2}{*}{ Strain (race) } & \multicolumn{3}{|c}{ Rice material } \\
\cline { 2 - 4 } & IRBLb-B & F-145-2 & Oil excellent63Shanyou63 \\
\hline $05-7(\mathrm{~A} 13)$ & $\mathrm{R}$ & $\mathrm{R}$ & $\mathrm{S}$ \\
$56(\mathrm{~A} 49)$ & $\mathrm{R}$ & $\mathrm{R}$ & $\mathrm{S}$ \\
$04-25(\mathrm{~A} 1)$ & $\mathrm{S}$ & $\mathrm{R}$ & $\mathrm{S}$ \\
$04-15(\mathrm{~A} 1)$ & $\mathrm{S}$ & $\mathrm{R}$ & $\mathrm{S}$ \\
$04-1(\mathrm{~A} 15)$ & $\mathrm{R}$ & $\mathrm{R}$ & $\mathrm{S}$ \\
$05-12(\mathrm{~B} 13)$ & $\mathrm{R}$ & $\mathrm{R}$ & $\mathrm{S}$ \\
$05-3(\mathrm{~B} 9)$ & $\mathrm{S}$ & $\mathrm{S}$ & $\mathrm{S}$ \\
$04-27(\mathrm{~B} 15)$ & $\mathrm{S}$ & $\mathrm{R}$ & $\mathrm{S}$ \\
$04-10(\mathrm{~B} 13)$ & $\mathrm{R}$ & $\mathrm{R}$ & $\mathrm{S}$ \\
$05-29(\mathrm{~B} 31)$ & $\mathrm{R}$ & $\mathrm{S}$ & $\mathrm{S}$ \\
\hline
\end{tabular}

$\mathrm{R}$ means disease resistance, $\mathrm{S}$ means disease susceptibility. Among the 10 tested strains, IRBLb-B and F-145-2 were resistant to 6 and 8 strains respectively, and the resistance frequencies were $60 \%$ and $80 \%$, respectively. The difference of resistance frequencies between them was $20 \%$. This indicated that Pib gene had good utilization value in disease resistance breeding, that is, the molecular marker of resistance genes in rice had strong validity

\section{Pib molecular marker assisted selection of rice blast resistance breeding}

In this paper, $600 \mathrm{~F}-2$ strains derived from IRBLb-B and F-145-2 hybridization were amplified by using the molecular marker-assisted method. The amplification results are shown in Table 4.

From Table 4, 185 homozygous plants of Pib gene were screened out from 600 F2 plants. At the same time, $600 \mathrm{~F} 2$ plants were used as materials to investigate the relationship between Pib gene and disease resistance in the field. The results showed that all Pib homozygous and heterozygous plants were resistant to the disease, while all Pib-free plants were susceptible to the disease. The results showed that the existence of Pib gene was consistent with the field resistance and the Pib gene was dominant.

\section{Application of Pib molecular markers in germplasm resources identification}

As we all know, germplasm resources (including wild and domesticated species) play an important role in both production practice and scientific research. In order to verify the consistency of Pib gene molecular markers with blast resistance, 122 hybrid rice parents or materials were tested by single race inoculation with blast fungus strains 
05-12 (ZB13) and 05-30 (ZC15). The results of Pib molecular identification are shown in Table 5. At the same time, the parent material is the basis of cultivating new crop varieties. Two pairs of dominant molecular markers Pibdom and Lys 145 were used to detect 122 parents or materials of Hybrid Rice by PCR. The results of PCR amplification were shown in Figure 1.

Table 4. Molecular test of Pib gene and its resistance to rice blast in the field

\begin{tabular}{c|c|c|c|c}
\hline Hybridized combination & $\begin{array}{c}\text { Disease } \\
\text { resistance } \\
\text { response }\end{array}$ & $\begin{array}{c}\text { Number of pure } \\
\text { plants with Pib } \\
\text { gene }\end{array}$ & $\begin{array}{c}\text { Number of } \\
\text { hybrid plants } \\
\text { with Pib gene }\end{array}$ & $\begin{array}{c}\text { Number of } \\
\text { plants without } \\
\text { Pib gene }\end{array}$ \\
\hline IRBLb-B/D62B & $\mathrm{R}$ & 28 & 46 & 0 \\
IRBLb-B/D62B & $\mathrm{S}$ & 0 & 0 & 26 \\
IRBLb-B/Shuhui363 & $\mathrm{R}$ & 35 & 44 & 0 \\
IRBLb-B/shuhui363 & $\mathrm{S}$ & 0 & 0 & 19 \\
IRBLb-B/Shuhui527 & $\mathrm{R}$ & 36 & 40 & 0 \\
IRBLb-B/shuhui527 & $\mathrm{S}$ & 0 & 0 & 24 \\
F-145-2/D62B & $\mathrm{R}$ & 27 & 45 & 0 \\
F-145-2/D62B & $\mathrm{S}$ & 0 & 0 & 28 \\
F-145-2/Shuhui363 & $\mathrm{R}$ & 32 & 38 & 0 \\
F-145-2/shuhui363 & $\mathrm{S}$ & 0 & 0 & 29 \\
F-145-2/Shuhui527 & $\mathrm{R}$ & 27 & 41 & 0 \\
F-145-2/shuhui527 & $\mathrm{S}$ & 0 & 0 & 32 \\
Total & & 185 & 254 & 158 \\
\hline
\end{tabular}

In the field resistance identification, 3 plants did not get results because of death

Table 5 shows that only 22 of 157 rice varieties contain the blast resistance gene Pib, while most varieties do not. The results showed that the molecular marker-assisted method could quickly and accurately identify rice germplasm resources containing Pib gene, and provide effective methods and scientific basis for selection of resistant parents in blast resistance breeding. At the same time, it can be seen from Figure 1 that the dominant molecular marker Pidom can specifically amplify a fragment about $350 \mathrm{bp}$ in size, and the dominant molecular marker Lys 145 can specifically amplify a fragment about 800 bp in size. In Figure 1, it can be seen that only 7 parents or materials of 122 hybrid rice contain blast resistance. Pib gene was not found in other parents or materials of hybrid rice.

Table 5. Molecular identification of Pib gene in rice varieties from different countries

\begin{tabular}{c|c|c}
\hline $\begin{array}{c}\text { Whether the disease resistance } \\
\text { gene Pib is present or not }\end{array}$ & Number of rice varieties & Representative rice varieties \\
\hline Pib & 22 & Special Qing, Tetep, Kaly etal \\
\hline No Pib & 135 & $\begin{array}{c}\text { Short for Zhejiang Province 733, } \\
\text { Japan clear, Wells etal }\end{array}$ \\
\hline
\end{tabular}

The existence of Pib gene is based on the amplification results of Pib dominant marker YL155/YL87 and susceptible allele Pib dominant marker YL155/YL87 


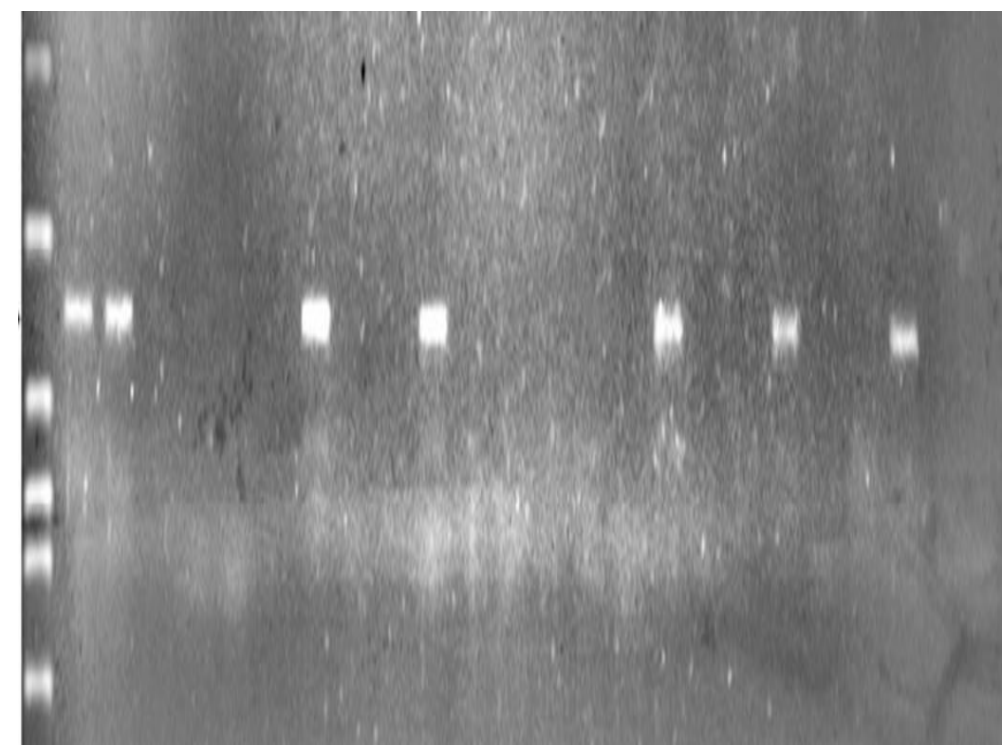

(a)

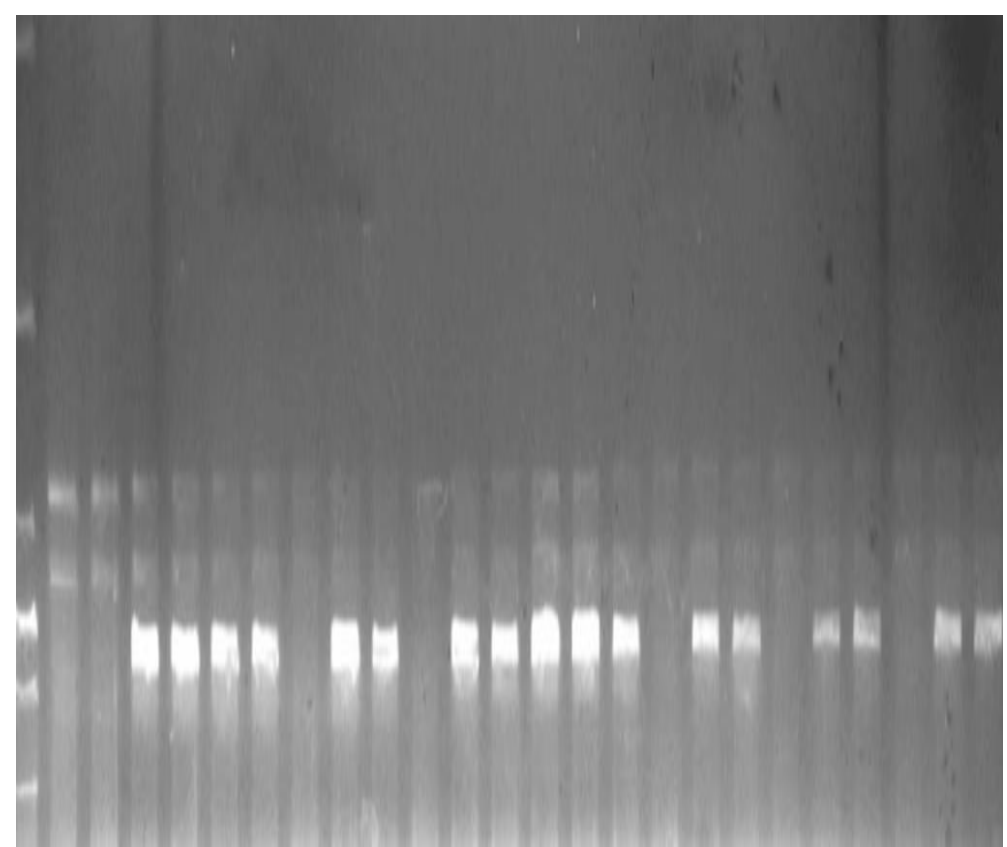

(b)

Figure 1. Results of PCR amplification of resistance genes in different rice varieties. (a) PCR amplification products of dominant molecular marker pibdom for disease resistance isogenes.

(b) Dominant molecular marker Lys145PCR amplification products of susceptible genes

\section{Resistance test of rice stripe blight}

\section{Molecular marker assisted effect}

In order to verify the effect of molecular marker-assisted resistance to rice stripe blight, a practical test and analysis are needed. The results are shown in Table 6 and Figure 2.

From Table 6, it can be seen that this method can better label the gene of rice stripe blight, and can accurately reflect the positive and reverse sequence of the gene and the 
location of the clone. At the same time, from Figure 2, it can be seen that most of the amplification results of $\mathrm{BC}_{3} \mathrm{~F}_{1}$ are the same as those of all the selected individuals, which indicates that other rice bodies have the same amplification results. It also contains the stripe blight gene.

Table 6. Analysis of marker results

\begin{tabular}{c|c|c|c}
\hline Tab & Forward sequence & Reverse sequence & $\begin{array}{c}\text { Where the clone is } \\
\text { located }\end{array}$ \\
\hline STS11-19 & ACGGTCGCTAGTATGTCCTG & CCTCGATAATGCACCTAAAT & AC135568 \\
STS11-31 & GGGCTTTCAACTCGTACTCTG & ATGAACTGCGGGTCCAATAA & AC136009 \\
STS11-43 & TAAGAAGGGCGAACAAAG & AACCACCGCTACCAAGAC & AC1332481 \\
STS11-71 & GGGTCCTGCCGAGATTTA & CCATCGTTGCCAGGTTAG & AC124151 \\
\hline
\end{tabular}

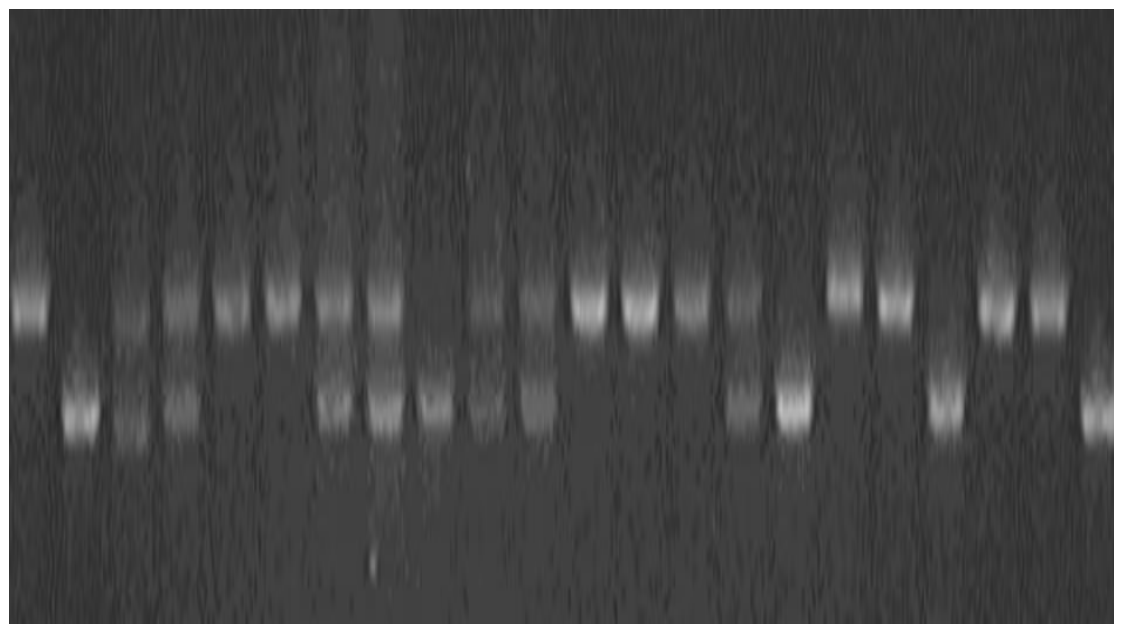

Figure 2. Amplification results

Molecular marker-assisted selection of backcross transfer stripe blight resistance genes

Marker-assisted selection (MAS) breeding was carried out according to the technical route. The acquisition of each backcross generation population and individual plant carrying disease-resistant genes was shown in Table 7.

Table 7. Detection of disease resistance per plant

\begin{tabular}{c|c|c|c|c}
\hline For generations & Plant coefficient & $\begin{array}{c}\text { Number of plants } \\
\text { detected }\end{array}$ & $\begin{array}{c}\text { Number of plants carrying } \\
\text { resistance genes }\end{array}$ & B/A \% \\
\hline $\mathrm{BC}_{1} \mathrm{~F}_{1}$ & 1 & 13 & 5 & 38.46 \\
$\mathrm{BC}_{2} \mathrm{~F}_{1}$ & 3 & 9 & 5 & 55.56 \\
$\mathrm{BC}_{3} \mathrm{~F}_{1}$ & 5 & 331 & 51 & 15.41 \\
$\mathrm{BC}_{4} \mathrm{~F}_{1}$ & 52 & 1297 & 407 & 31.38 \\
$\mathrm{BC}_{2} \mathrm{~F}_{2}$ & 4 & 139 & 17 & 12.23 \\
$\mathrm{BC}_{3} \mathrm{~F}_{2}$ & 51 & 1066 & 218 & 20.45 \\
\hline
\end{tabular}

The $\mathrm{BC}_{\mathrm{n}} \mathrm{F}_{1}$ population was detected as a hybrid plant with disease resistance gene, and the $\mathrm{BC}_{\mathrm{n}} \mathrm{F}_{2}$ population was detected as a homozygous plant with disease resistance gene 
From Table 7, it can be seen that with the increase of backcross generations, backcross and inbred population gradually expanded. A total of 407 plants containing heterozygous resistance genes were obtained by $\mathrm{BC}_{4} \mathrm{~F}_{1}$ and 218 plants containing homozygous resistance genes were obtained by $\mathrm{BC}_{3} \mathrm{~F}_{2}$. It is hopeful to select new lines with good disease resistance from these offspring. After marking resistance genes by molecular marker-assisted method in this paper, the effect of selecting rice breeding is better.

\section{Identification of resistance to stripe blight}

The resistance of $\mathrm{BC}_{2} \mathrm{~F}_{3}$ strains with homozygous resistance genes and their parents to natural insects was identified. The incidence and disease grade index of rice were investigated after the disease condition was stable. The results were shown in Table 8.

Table 8. Results of the survey

\begin{tabular}{c|c|c|c}
\hline Strain number & Disease grade index & Plant incidence rate & Resistance level \\
\hline E1 & 5.20 & 11 & $\mathrm{R}$ \\
E2 & 0.45 & 2 & $\mathrm{R}$ \\
E3 & 3.80 & 8 & $\mathrm{R}$ \\
E4 & 0.61 & 2 & $\mathrm{R}$ \\
E5 & 3.00 & 4 & $\mathrm{R}$ \\
E6 & 16.00 & 31 & $\mathrm{R}$ \\
E7 & 10.20 & 14 & $\mathrm{R}$ \\
E8 & 8.80 & 12 & $\mathrm{R}$ \\
E9 & 3.80 & 5 & $\mathrm{R}$ \\
E10 & 10.00 & 14 & $\mathrm{R}$ \\
E11 & 5.85 & 8 & $\mathrm{R}$ \\
E12 & 3.61 & 6 & $\mathrm{R}$ \\
E13 & 8.00 & 9 & $\mathrm{R}$ \\
E14 & 6.80 & 12 & $\mathrm{R}$ \\
E15 & 8.80 & 16 & $\mathrm{R}$ \\
E16 & 10.90 & 6 & $\mathrm{R}$ \\
E17 & 4.60 & 15 & $\mathrm{R}$ \\
E18 & 10.60 & 85 & $\mathrm{R}$ \\
CK & 85.00 & $\mathrm{HS}$ \\
\hline
\end{tabular}

From Table 8 , it can be seen that the incidence rate of indica rice is $85 \%$, the disease grade index is 85.0, and the resistance level belongs to high susceptibility. Among 18 $\mathrm{BC}_{2} \mathrm{~F}_{3}$ lines carrying homozygous resistance genes, the highest disease grade index is only 16.0, and the lowest is 0.45 . The resistance level to stripe blight belongs to resistance level, which indicates that the resistance level to stripe blight is assisted by molecular markers in this paper. Later, the re-harvested indica rice had better resistance to stripe blight.

\section{Discussion}

With the development of industrial and agricultural production, the discharge of three wastes, the exploitation and utilization of minerals, sewage irrigation and the use of pesticides, herbicides and fertilizers have seriously polluted the soil, water quality 
and atmosphere, resulting in environmental deterioration and causing immeasurable harm to society, economy and human beings. Excess heavy metals can hardly be eliminated once they enter the environment, especially in the soil. In addition, there is a trend of organic in the organism, so heavy metal pollution has a greater hazard. Through actual investigation and analysis, it is found that many heavy metals are essential trace elements for natural plants, and play a very important role in the growth and development of natural plants. However, when the amount of heavy metals in the environment exceeds the even-critical point, it will have a certain toxic effect on plants. In light of this, the lower processes in plants will be disordered, growth and development will be inhibited, and the heavy metals will change the genes in plants, leading to a variety of diseases in plants and eventually leading to plant death. Taking rice as an example, the main heavy metal resistance in rice was blast resistance and stripe blight resistance. Therefore, molecular marker-assisted method should be used to label rice blast resistance and stripe blight resistance, so as to shorten breeding years, improve the selection efficiency, enhance the heavy metal resistance of natural plants, and promote the growth and development of natural plants.

The significance of marker-assisted genes was found through the above studies. Molecular marker-assisted selection (MAS) is an important means of crop breeding, which uses molecular markers closely linked to target genes to select genotypes, and is not affected by environmental conditions. MAS can shorten breeding years and improve selection efficiency. However, the recombination rate between target traits and markers is different in different populations, and often the target traits are not breeding populations. Therefore, in practical application, the recombination rate of molecular markers and target traits for assisted selection must be low, so it is greatly limited. Therefore, the best way is to use the resistance gene itself to establish the corresponding molecular markers. Cloning of disease-resistant genes provides the possibility of establishing such markers. Wang established the molecular marker of Pi-ta gene based on the PI-ta gene which has been cloned. These markers were successfully applied to rice blast resistance assistant breeding. This kind of marker is defined as functional gene-assisted selection. The molecular marker of Pib gene mentioned in this paper is based on the disease-resistant gene Pib itself. It is of great significance to select target genes accurately by using these markers, to speed up the screening of resistant sources, to identify resistant genes and to breed rice varieties with high resistance ( $\mathrm{Li}$ et al., 2017).

Studies on the marker-assisted gene of rice Pib show that previous scholars could only detect whether the material contained the disease-resistant gene Pib when using the dominant molecular marker Pibdom molecular detection, and could not directly determine the homozygous disease-resistant gene Pib material. If homozygous plants are to be selected, they need to be differentiated by several generations of field resistance identification, which is time-consuming and vulnerable to environmental impact without accurate results. In this paper, a set of molecular markers of resistance gene Pib itself was established by using dominant molecular markers Pibdom and Lys 145 for molecular detection. Combined with Yangzhou Jiadai, homozygous plants containing resistance gene Pib could be selected in F2 generation of hybrid isolation within one year, and the results were identical through field resistance identification. The results showed that the homozygous plants containing Pib gene could be selected quickly and accurately by using this set of molecular markers, which could simplify the complicated identification of resistance in the field. Most parents and combinations of 
hybrid rice currently used in production are not resistant to rice blast. Pib gene is a major disease resistance gene, which is a good choice in disease resistance breeding. By using these molecular markers, the blast resistance gene Pib can be quickly and accurately selected from numerous rice resources. The parents selected by this marker can transfer Pib resistance gene into rice varieties by conventional hybridization breeding method to produce resistance. At the same time, other resistance genes and Pib genes can be aggregated into the same fine varieties by MAS technology to produce durable resistance and to maintain the best varieties to the greatest extent. By using STS and SSR markers OSR20, OSR32, RM213, RM207 and RM262 closely linked to disease resistance genes, Chen Xuewei et al. tracked and screened rice blast resistance genes. Pi-d(t)1, Pib and Pi-ta2 were aggregated into G46B. In a relatively short time, relatively durable resistant strains of several physiological races were developed. Our laboratory is using this kind of molecular marker to polymerize Pib and Pi-ta multiple blast resistance genes, so as to further use Pib gene to breed persistent resistant varieties and lay the foundation for the ultimate goal of rice disease resistance breeding.

At the same time, the resistance of rice stripe blight was studied. It was found that this method could improve the resistance of rice stripe blight. It was found that Dular had strong resistance to stripe blight, but its agronomic morphology was not good. In practical application, because of rice hybridization, the characters of both donor and recipient are quite different, and they are severely separated in the lower generations of backcross, so it is difficult for the characters to return to the status of recipient parents. Fertility and character segregation still existed in the offspring of Indica Rice crossed with Dular to $\mathrm{BC}_{4} \mathrm{~F}_{1}$ in this experiment. This needs to be solved by increasing the number of backcross to break the linkage between unfavorable trait genes and good trait genes, or by enlarging backcross population and increasing selection pressure. Indica rice is a semi-erect panicle variety. If the erect panicle-type indica rice varieties with resistance to stripe blight, such as Zhendao 88, Zhendao 99 and Xudao 3, were selected or bred in recent years as resistant donor parents, the speed of backcross improvement might be accelerated. Of course, this is only considered from improving the resistance of recipient parents by backcrossing, so that the comprehensive traits of offspring can be completely restored to the status of recipient parents. If we want to breed new varieties resistant to stripe blight, we need to increase the character differences between donor and recipient parents, which is more conducive to enriching variation and breeding varieties beyond recipient parents. If five $\mathrm{BC}_{2} \mathrm{~F}_{3}$ lines of Indica Rice crossed with Dular were screened out in the experiment, their yield would be much higher than that of Indica rice. In conclusion, this method can significantly enhance the resistance to heavy metals and promote the healthy growth of rice after analyzing the marker-assisted heavy metal resistance of rice.

\section{Conclusions}

In order to enhance the heavy metal resistance of natural plants and improve the survival and development ability of natural plants, it is necessary to use molecular marker-assisted method to label heavy metal resistance genes of natural plants, select natural plants, accelerate the speed of crop improvement and improve the level of crop improvement. In this paper, rice was taken as an example for specific analysis. Through practical analysis, it was found that rice heavy metal resistance was mainly composed of blast resistance and stripe blight resistance. Molecular marker-assisted method was 
needed to label rice blast resistance genes and stripe blight resistance genes. Higher resistant rice was selected to improve rice quality. It was found that the molecular marker of rice resistance gene could retain the basic characteristics of rice and enhance the heavy metal resistance gene of rice, which plays a new role in production, and breeding new disease-resistant varieties. Due to the limited time, this paper only chooses rice as the research object, which has one-sidedness, so more natural plants need to be selected as the research object, which lays the foundation for the research of heavy metal resistance genes in natural plants.

Acknowledgements. This research was supported by Scientific and Technologial Innovation Programs of Higher Education Institutions in Shanxi (No. 2019L0943).

\section{REFERENCES}

[1] Beohar, A., Yadav, N., Vishvakarma, S. K. (2018): Analysis of trap-assisted tunnelling in asymmetrical underlap 3D-cylindrical GAA-TFET based on hetero-spacer engineering for improved device reliability. - Iet Micro \& Nano Letters 12(12): 982-986.

[2] Chen, J. B., Chen, A. L. (2017): An improved active frequency offset island detection algorithm. - Journal of Power Supply 15(3): 140-147.

[3] Danilova, M. N., Kudryakova, N. V., Doroshenko, A. S. (2016): Molecular and physiological responses of Arabidopsis thaliana plants deficient in the genes responsible for $\mathrm{ABA}$ and cytokinin reception and metabolism to heat shock. - Russian Journal of Plant Physiology63(3): 308-318.

[4] Dong, M. A., Lu, H., Cai, S. (2019): Molecular mapping of stripe rust resistance gene YrH9017 in wheat - Psathyrostachys huashanica introgression line. - Journal of Integrative Agriculture 18(1): 112-118.

[5] Gherib, A., Djebaili, H., Bouchaala, L. (2017): Physiological and biochemical markers in the process of resistance and/or tolerance of heavy metals in the abandoned mining area of Sidi Kamber, Skikda, Algeria. - International Journal of Environmental Studies 74(2): $1-15$.

[6] Hu, S. B., Zhou, Q., An, J. (2016): Cloning PIP genes in drought-tolerant vetiver grass and responses of transgenic VzPIP2;1 soybean plants to water stress. - Biologia Plantarum 60(4): 655-666.

[7] Huang, Z., Zhang, X., Jiang, S. (2017): Analysis of cold resistance and identification of SSR markers linked to cold resistance genes in Brassica rapa L. - Breeding Science 67(3): 213-220.

[8] Jimenez, F., Rojano-Delgado, A. M., Fernández, P. T. (2016): Physiological, biochemical and molecular characterization of an induced mutation conferring imidazolinone resistance in wheat. - Physiologia Plantarum 158(1): 2-10.

[9] Kusch, S., Pesch, L., Panstruga, R. (2016): Comprehensive phylogenetic analysis sheds light on the diversity and origin of the MLO family of integral membrane proteins. Genome Biology \& Evolution 8(3): 878-895.

[10] Li, J. Q., Sun, E. C., Wang, Z. (2017): Software definition wireless network - overview and prospect. - Journal of China Academy of Electronics and Information Technology 12(6): 570-578.

[11] Liang, B. Y., Peng, L. (2017): Molecular screening of blast resistance genes in rice germplasms resistant to Magnaporthe oryzae. - Rice Science 24(1): 41-47.

[12] Peng, P., Cheng, H. X., Chen, X. C. (2017): SOC estimation of lithium battery based on adaptive Kalman filter. - Chinese Journal of Power Sources 41(11): 35-38. 
[13] Salgaonkar, B. B., Das, D., Bragança, J. M. (2016): Resistance of extremely halophilic archaea to zinc and zinc oxide nanoparticles. - Applied Nanoscience 6(2): 251-258.

[14] Shah, L., Rehman, S., Ali, A. (2017): Genes responsible for powdery mildew resistance and improvement in wheat using molecular marker-assisted selection. - Journal of Plant Diseases \& Protection125(7426): 1-14.

[15] Song, B. (2017): Research on construction technology and engineering management of water conservancy and hydropower project. - Automation \& Instrumentation 63(10): 170-171.

[16] Sun, J. Y., Zhao, Y., Wang, S. G. (2018): Improvement of SIFT feature matching algorithm based on image gradient information enhancement. - Journal of Jilin University (Science Edition) 56(1): 82-88.

[17] Wang, P., Wang, L., Guo, J. (2016): Molecular mapping of a gene conferring resistance to Phytophthora capsici Leonian race 2 in pepper line PI201234 (Capsicum annuum L.). Molecular Breeding36(6): 1-11.

[18] Wang, Y. P., Jia, J., Song, N. X. D. (2017): Dynamic simulation and experimental study of loader working device. - Computer Simulation 34(7): 184-187.

[19] Wang, Y. X., Hu, Y., Chen, B. H., Zhu, Y. F., Dawuda, M. M., Svetla, S. (2018a): Physiological mechanisms of resistance to cold stress associated with 10 elite apple rootstocks. - Journal of Integrative Agriculture 17(4), 857-866.

[20] Wang, Z. Z., Xie, J. Z., Li, G. (2018b): Molecular mapping of YrTZ2, a stripe rust resistance gene in wild emmer accession TZ-2 and its comparative analyses with Aegilops tauschii. - Journal of Integrative Agriculture 17(6): 1267-1275. 